J. Egypt. Soc. Parasitol. (JESP), 50(3), 2020: 547-556

(Online: 2090-2549)

\title{
ULTRASTRUCTURAL AND IMMUNOHISTOCHEMICAL ALTERATIONS IN HEMOCYTES AND FAT BODY OF THE FLESH FLY (SARCOPHAGA ARGYROSTOMA) LARVAE UPON CANCER CELL LINE INOCULATION
}

\section{By}

LINA A. ABOU EL-KHASHAB ${ }^{1}$, SHAYMAA H. MAHMOUD ${ }^{2}$, WALAA A. MOSELHY ${ }^{1}$, ABDELBASET B. ZAYED ${ }^{1}$ and MOHAMED S. SALAMA ${ }^{3}$

Department of Zoology and Entomology ${ }^{1}$, Faculty of Science, Al-Azhar University

(Girls branch), Nasr City, Cairo, Department of Zoology², Faculty of Science, Menou-

fia University, Menoufia, and Department of Zoology ${ }^{3}$, Faculty of Science,

Ain Shams University Cairo, Egypt ( ${ }^{*}$ Correspondence: linaabdelazez@yahoo.com)

\begin{abstract}
In this study, hemocytes and fat body changes were investigated after activation the immune response of the third instar larvae of Sarcophaga argyrostoma by injecting the larvae with MDA-MB-231cancer cell lines. To investigate the changes in hemolymph and fat body tissue, light and transmission electron microscopy (TEM) were used. Apoptosis demonstration in the larval flesh fly after injection was immunohistochemically tracked using a marker of caspase initiator activity; namely caspase- 3 antibody.The results showed remarkable changes in morphology, viability and the spreading ability of immunocompetent hemocytes and fat body cells between normal and immunized $S$. argyrostoma larvae. In hemocytes, multicellular aggregates were formed to entrap invading cancer cells, in addition to membrane blebbing, cytoplasm vacuolization, cell and organelle swelling, and chromatin condensation. Meanwhile, in fat body cells of injected larvae, depletion of lipid droplets, changes in the appearance of protein granules and degrade of basement membrane overlying the fat body were observed. These features are typical for apoptotic and autophagal cell death which were confirmed by detection of apoptotic fat body cells after cancer cell injection using activated caspase-3 immunostaining.

Keywords: Fat body cells, Hemocytes, Sarcophaga argyrostoma, Cancer cell, Caspase 3, Apoptosis, Ultrastructure, Immunohistochemistry, TEM.
\end{abstract}

\section{Introduction}

The flies grow and survive in dirty places, so it is believed to have strong antimicrobial peptides (Ahamad et al, 2012), which may have direct impact on cancer cells (Ratcliffe et al, 2014; Shehata et al, 2016). One of the important medical insects is flesh fly found worldwide and can transmit human pathogens and zoonotic agents, however they rarely to be infected (Scott et al, 2014). So, when the insects were infected by the invading cells, the pattern recognition proteins/ receptor (PRPs) in insects would firstly recognize, and then initiate the activation and regulation of a series of innate immune response (Ohta et al, 2006).

The first line of insect defense consists of physical barriers such as the outer exoskeleton, the chitinous linings of midgut and trachea (Masova et al, 2009). Many pathogens or foreign bodies are able to overcome the first line of host defense and get into the body. Foreign cells in the hemocel activated systemic immune mechanisms, which consisted of cellular and humoral immunity (Lemaitre and Hoffmann, 2007; Jiangfan et al, 2016). Hemocytes being precursor of innate immunity in insects, a strong correlation between hemocyte number and immune response (Mishra et al, 2015). Parasitoid wasp infection in $D$. melanogaster induces a number of significant increases in total hemocytes (Russo et al, 2001). Considerable variations in the relative densities of various hemocyte in the infected house flies indicated stress development during infection (Mishra et al, 2015). The stress developed in hemocyte indicated the change in immunity (Ribeiro and Brehélin, 2006). The number and types of hemocytes showed variability within species, depending on developmental and physiological stages (King, 2013). Granulo- 
cytes (Gr) and plasmatocytes (Pl) are the hemocytes adhering to foreign bodies that enabled them to participate in phagocytosis, encapsulation, and nodulation (Lemaitre and Hoffmann, 2007). So, hemocytes have an important role in recognition of foreign bodies as cellular immune mechanisms of insects (Hillyer, 2016). Also, insect fat body form a myriad of metabolic functions including the homeostatic maintenance of hemolymph proteins, lipids, and carbohydrates (Haunerland and Shirk, 1995). As the principal metabolic-storage tissue, fat body is structurally organized to provide maximal exposure to the hemolymph and well-suited for both absorbing and releasing metabolites (Keeley, 1985). Fat body cells, known as trophocytes, clustered together by a thin basal lamina that expands into the hemocoel and forms amorphous lobes or ribbons that increase the organ surface area, which in turn enhance exchange of substances between the organ and hemolymph (Arrese and Soulages, 2010), responsible for about $90 \%$ of hemolymph proteins (Nappi, 1981), and play a vital role in foreign bodies elimination.

Although, invading cells developed mechanisms deleteriously affecting body tissue to overcome immune responses of the larvae (Chakrabarti et al, 2012), immune activation results in significant changes in insect hemocytes can overcome this deleterious effects(Russo et al, 2001).

The present study aimed to identify alterations in immune response resultant from experimental cancer cell line injection at the histological and immunohistochemical level.

\section{Materials and Methods}

A colony of $S$. argyrostoma was maintained in the insectary of Zoology and Entomology Department, Faculty of Science, Al-Azhar University (girls branch), under controlled conditions $\left(25 \pm 5^{\circ} \mathrm{C}, 60 \pm 10 \% \mathrm{RH}\right.$ and 12-12 light-dark photoperiod). Adults were fed on $10 \%$ sucrose solution while larvae were reared on bovine meat (Bai and Degheele, 1988).

Third larval instars of $S$. argyrostoma were microinjected with $1 \mu$ of human breast cancer cells (MDA-MB-231). Cells were loaded into needle at a density of about 3000 cells $/ \mathrm{ml}$, between the first and second abdominal segments using a sterile thin-needle micro-syringe (Takahashi et al, 1986). Cancer cells were obtained from VACSERA, Egypt. Healthy, non-injected larvae were used as control individuals. Then, the haemolymph were collected and fat body was excised from injected and non-injected larvae at $24,48 \& 72 \mathrm{hr}$ post-injection.

Microscopic examination: The hemocytes were isolated from hemolymph by centrifugation, and then both hemocyte and fat body were immediately immersed in 5\% glutaraldehyde in $0.1 \mathrm{M}$ sodium cacodylate buffer ( $\mathrm{pH} 7.4$ ) for $4 \mathrm{hr}$ at room temperature. Following three washes in $0.1 \mathrm{M}$ sodium cacodylate buffer, samples were subjected to secondary fixation in $1 \%$ osmium tetroxide in the same buffer for $2 \mathrm{hr}$ at room temperature. They were washed in $0.1 \mathrm{M}$ cacodylate buffer three times; dehydrated in an ethanol series $30 \%, 50 \%, 70 \%, 90 \%$ \& $100 \%$ at room temperature. The tissue pieces were transferred to acetone and infiltrated with Embed 812 epoxy resin in a stepwise manner with ratios of acetone to embed of 1:2, 1:1 \& 2:1 and then transferred into pure resin. Each infiltration step was allowed to proceed from $30 \mathrm{~min}$ to 1 day. The resin was polymerized at $60^{\circ} \mathrm{C}$ for $48 \mathrm{hrs}$ and then allowed to attain room temperature. For light microscopy, semi-thin sections $(1 \mu \mathrm{m})$ were stained with $0.5 \%$ toluidine blue in aqueous solution. For TEM, ultra-thin sections $(50-80 \mathrm{~nm})$ of tissue were transferred to copper grids, stained with uranyl acetate and lead citrate, washed in $0.02 \mathrm{~N} \mathrm{NaOH}$ followed by distilled water and left on a filter paper in a Petri-dish prior to examination (Bozzola and Russell, 1999). Stained sections were examined with a TEM (JEOL-JEM 1010) at $80 \mathrm{KV}$ at the Regional Center for Mycology and Biotechnology (RCMB), Al-Azhar University.

Detection of apoptotic cells in larval tissues by activated caspase- 3 immunohisto- 
chemistry: For imunohistochemical examination, individuals of the $3^{\text {rd }}$ instar larva were taken from each time post injection and from control ones with nearly the same size. The whole larvae were dissected transversally into two halves by means of an anatomic pincers and a new lancet blade for each larva and fixed in $4 \%$ paraformaldehyde for 35 $\mathrm{min}$ at room temperature (Bancroft and Cook, 1994). The fixed samples were washed three times in 1x Phosphate-buffered saline with Triton-X-100 (PBT) (1x PBS with $0.3 \%(\mathrm{v} / \mathrm{v})$ Triton X-100), each for $5 \mathrm{~min}$ at room temperature. The samples were blocked 20min with PBST-S (2\% bovine serum albumin) and 50min with PBST-S-S (2\% sheep serum (Sigma-Aldrich) in PBST-S). Samples were incubated with caspase-3 primary antibody (Asp 175) diluted 1:200 with 1x PBS overnight at $4^{\circ} \mathrm{C}$. After five washes in PBST, samples were blocked 15 min with PBST-S and 50 min with PBST-S-S. Secondary antibody used was 1:100anti-rabbit (Klepsatel et al, 2016). Slides were washed with $0.05 \%$ solution of Tween ${ }^{\circledR} 20$ in $1 \times$ PBS twice for $5 \mathrm{~min}$ and washed in water for $1 \mathrm{~min}$ each. Slides were lightly counterstained in hematoxylin at room temperature for about 10s, washed with two changes of distilled water, followed by $95 \%$ ethanol twice for $2 \mathrm{~min}$ each, $100 \%$ ethanol twice for 3 min each and with two changes of xylene. Finally, a coverslip was applied carefully on samples and sealed on at least two sides with clear nail polish. Slides were kept in the dark at $4^{\circ} \mathrm{C}$ until imaging. Images were captured by an Olympus light microscope at the Regional Center for Mycology and Biotechnology (RCMB), Al-Azhar University.

Using image analysis software (ImageJ), the $\%$ stained area was quantified via measuring total area (brown \& non-brown staining) and the immune histochemical (IHC) stained area (brown staining) and then relate this as a percentage. In histological sections, the apoptotic index (apoptotic cells\% per total number of cells) was quantitative apoptosis measurement (Duan et al, 2003).

\section{Results}

Microscopic examination of hemocytes and fat body sections stained with toluidine blue revealed obvious morphological changes due to challenge at different time intervals post injection compared to normal samples. The results showed an increase in number of hemocytes in hemolymph of induced larvae. The preparations made from hemocyte collected $24 \& 48 \mathrm{hr}$ after injection revealed the presence of hemocytes aggregations forming nodule around the injected material. These structures disappeared at the final stages of injection at $72 \mathrm{hr}$ PI (Fig.1).

By TEM morphology of the control hemocytes showed plasmatocytes (Pl), granulocytes (Gr), spherulocytes (Sp), and oenocytoids (Oe) (Figs. $2 \& 3$ ).

Pls are large cells; its nucleus is round to ovoid and contained scattered chromatin and distinct envelope, while Grs are variable in sizes, round to oval in shape and they characterized by the presence of numerous and different structured granules with different shapes and sizes in their cytoplasm. Oes were medium to large, round or oval cells with an eccentric nucleus. SPs are often very large hemocytes; round to ovoid in shape and their cytoplasm are filled with largesized inclusions known as spherules and obscure the small nucleus (Fig. 2). After injection of the $S$. argyrostoma larvae with cancer cells, hemocytes entrapped the foreign cells and became phagocyte and their ultrastructure were changed. It is obvious at $24 \mathrm{hr}$ post injection irregular appearance of cell membrane of Gr \& Pl was determined; numerous vacuoles filled with heterogeneous materials were in the cytoplasm. Meanwhile, at $48 \mathrm{hr}$ post injection, the membrane was blebbed and chromatin was condensed in comparison to the control cell. At $72 \mathrm{hr}$ P.I., there was no $\mathrm{Pl}$ and $\mathrm{Gr}$ specific for this species were detected, the cytoplasm was extensively vacuolated and many cells were totally disintegrated (Fig. 3). The light microscopic examination of the fat body tissues of the control larvae showed their large central- 
ly located nuclei, several prominent vacuoles, and lipid droplets distributed throughout the cytosol (Fig. 4). Besides, the lipid droplets, many protein granula and glycogen rosettes were seen. While fat body from injected larvae, displayed characteristics typical of swollen cell and the nuclei of fat body cells having increased diameter. The lipid droplets in the fat cells were highly affected by injection with cancer cells. Additionally protein granula changed in their appearance. There was also damaging in basement membranes and hemocytes appear to be present at some sites of basement membrane damage. Similarly, transmission electron micrographs revealed that the lipid droplets reduced in the fat cells after $24,48 \& 72 \mathrm{hr}$ and it is obvious distinguishable ultrastructure of nuclei, vacuoles, and lipid droplets in fat body between control and injected larvae. The fat body of injected larvae showed vacuolization, low cytoplasmic content, and loosening of cell followed by totally disintegration of many cells (Fig. 5).

The immunohistochemical analysis for the detection of the apoptotic cells in the fat body of $S$. argyrostoma larvae with anticaspase-3 were performed, paraffin sections that were immunostained with antibody showed activated caspase- 3 in the larvae of $S$. argyrostoma and the activated areas of caspase-3-labelled cells stained brown. Activated caspase-3-immunolabelled cells in control larvae at $24,48 \& 72 \mathrm{hr}$ showed few apoptotic cells with expression value for caspase-3 of $3.6 \pm 3.2 \%, 9.2 \pm 2.6 \%, 17.15 \pm 3.4$ $\%$ respectively, whereas many cells found positive for caspase- 3 in the fat body of the injected larvae (Figure 6). Significantly, the highest expression value for Caspase 3 (by area percentage) was observed at $72 \mathrm{~h}$ after injection (Caspase 3: $81.5 \pm 6.2 \%$ ), where at 24 \& 48hr P.I., values were Caspase 3: $37.52 \pm 5.3,60.23 \% \pm 11.7$, respectively.

\section{Discussion}

Insects lack the adaptive immune responses typical of vertebrates; thus, they were heavily dependent on their innate immune system to defend against different invasions. Knowledge on how the insect innate immune response to fight foreign body aided to understand the first step in human diseases interaction (Wang et al, 2013; Singh et al, 2014; $\mathrm{Wu}$ et al, 2014; Khalil et al, 2015). Injury, rolling and ingestion methods are techniques of insect infection that have been successfully established (Jiangfan et al, 2016). The injury method mainly used needles to deliver foreign bodies by piercing the somatic layer or directly injects foreign cell into the insect coelom to cause acute infection and rapidly activate immune response (Matsumoto et al, 2012).

The present study documented that injection of cancer cell lines in S. argyrostoma larvae induced activation of cellular and humoral defense mechanisms. Microscopic visualization showed an increase in number of hemocytes at the initial phases of injection and continued to increase till the last the experimental time compared with the normal larvae. The increase in hemocytes number in hemolymph of insects was a normal response to infection (Nappi, 1981; Eslin and Prevost, 1996). Similar observation was recorded in Drosophila melanogaster, when the pathogens in hemocoel stimulated increasing the number of the cells in hemolymph (Russo et $a l, 2001)$. Also, increase in number of hemocytes was in Anopheles gambiae upon infection with Escherichia coli (King, 2013). These reports suggested that, insect hemocells were constantly regenerated and kept a dynamic change during insect infection (Jiangfan et al, 2016; Mishra et al, 2015). The hemocytes formed multicellular aggregates, i.e., nodules, at the first period post injection that aided to entrap the invading cancer cells. The hemolytic were uniformly distributed in hemolymph of normal silkworms, but when larvae were injected with Escherichia coli, the cells agglomerate into clusters, and then melanized emerge, enhance, or vanish the exhibiting circulating hemocytes changes on morphology in hemocoel (Li et $a l, 2019)$. Besides, the morphological switch 
from round hemocytes into spindle cells in the third day post injection, which participated in the encapsulation process (Mizerska-Dudka and Andrejko, 2014). These results suggested that encapsulation and nodulation were involved in the cellular immune response processes for fast elimination of invaders in S. argyrostoma larvae. Several cellular mechanisms were well documented, such as phagocytosis, encapsulation and nodules formation (Lemaitre and Hoffmann, 2007; Mishra et al, 2015). Transmission electron microscopy confirmed that S. argyrostoma larvae injected with cancer cell resulted in sever damages of hemocytes, because the plasma membranes were changed (cell membrane was blebbed), vacuolization, low cytoplasmic content, nuclear changes (nuclear condensation) and loosening of cell followed by totally disintegration of many cells. The ultrastructural conditions in the hemocytes of the injected larvae may be induced by the cancer cell effect. These results agreed with studies on Galleria mellonella hemocytes (Mizerska-Dudka and Andrejko, 2014), the influence of infection with an entomopathogenic strain of Pseudomonas aeruginosa was investigated; additionally, hemocytes were changed in Apis mellifera naturally infected with Paenibacillus larvae (Zakaria, 2007). Also, the change in hemocyte types in Schistocerca gregaria was recorded after injection with Bacillus thuringiensis (Barakat et al, 2002). So, difference in hemocyte between normal and stressed larvae showed that the host defense system was activated (Nappi, 1981; Brehélin, 1982). Larvae of flesh fly like some other insects have humoral hemocytes concentrated in the last segments and scattered around tissues and organs (Jiangfan et al, 2016). Some of invaders were able to persist between the inner side of the body wall and muscle tissue layers because of the low concentration of hemocytes in these spaces, so they stayed in these locations and were not eliminated immediately (Chen et al, 1997). It was reported that, when the invaders disseminated into the hemocoel, they infected some internal organs, as fat body, epidermis and tracheal matrix (Wu et al, 2014; Feng et al, 2007).

In this study, light and TEM micrograph of fat body cells showed that lipid droplets in fat cells were highly affected by cancer cells treatment; the lipid droplets reduced in the fat cells after $24,48 \& 72 \mathrm{hr}$ of injection, revealing that after cancer cell injection, energy-supplying processes occurred. So, one possible explanation is that after injection, the energy demands (higher metabolic rate) exceed the energy acquisition, with consequent energy deficit being covered by utilization of lipid reserves. Also, the reduction in lipid droplets and glycogen rosettes occurred in t fat body of the fruit fly Drosophila melanogaster after stress exposure (Klepsatel et al, 2016). But, the present study sharp elevations in fat body lipids levels were detected in S. bullata following parasitism, envenomation, and artificial venom injections (Rivers et al, 2011). Also, the results showed that protein granula in fat body changed indicated that partly disintegrated protein granula probably supply compounds for the restoration of proteins engaged in the vital processes (Lipovšek et al, 2017). Tthus, after injection with cancer cell the morphological and ultrastructural changes indicated particular type of cell death. The general features typical for apoptosis were blebbing, chromatin condensation and autophagal cell death with vacuolization (Mizerska-Dudka and Andrejko 2014). So, cell death after injection played a dual role in foreign cell elimination or in survival and dissemination as the caspases are marker proteins with a pivotal role during caspase-dependent apoptosis (Labbe' and Saleh, 2008). Caspases were detected in insects (Ahmad et al, 1997; Gao et al, 2013), and similar to some caspase $3 \&$ 7 , enzymes engaged in the effector step of apoptosis in vertebrates (Xia et al, 2005). Roles of caspases in the fly went beyond traditional cell death (Chowdhury et al, 2008). In this work activation of caspase- 3 in the larval tissues of $S$. argyrostoma after injec- 
tion suggested that the high expression of caspase-3 contributes to apoptosis of fat body cells as an alternative response to cancer cell injection that allow subsequent cellular immune responses. The results agreed with Kültz (2005) who reported that caspase and other proteins with similar roles in multiple stress response pathways likely are keys to how cells encountering stress decide between induction of apoptosis versus cell cycle delay and repair. Also, the apoptosis of circulating hemocytes occurred in G. mellonella larvae after exposure to virulent substance due to an autophagic cell death process induced by stress and caspase- 3 was activated (Li et al, 2019).

\section{Conclusion}

The morphology and ultrastructural of $S$ argyrostoma larva injected with cancer cell between $24 \& 72 \mathrm{hr}$ PI, involved a series of stages, including injection, immune response and elimination of the foreign cell, and the flesh fly immune response was involved in the feature of hemocytes. Also, changes occurred in larval fat body correlated to apoptotic removal of damaged fat storage cells in response to injection, proved apoptosis a defense mechanism in insect immune system.

\section{Acknowledgement}

Authors would like to thank Al-Azhar University and Genetic Engineering laboratory, Entomology Department, Faculty of Science, Ain-Shams University for facilitated the experiments.

Author Contributions: Conceptualization, MS, \& SM, Methodology, LA, \& SM, Software, SM, Validation, WA, AZ, \& MS, Analysis, LA, Investigation, SM, \& LA, Resources, MS, \& WA, Data Curation, SM, WA, \& MS, Draft Preparation, SM, \& LA, Reviewing, WA, AZ, \& MS, Visualization, SM, WA, AZ, \& MS.

\section{References}

Ahamad, MNU, Mojumder, S, \& Asing, DS, 2012: Antimicrobial and cytotoxic activities of larval extract of Musca domestica (house fly). Int. J. Curr. Res. Rev.4:63-9.

Ahmad, M, Srinivasula, SM, Wang, L, Litwack, G, 1997: Fernandes-Alnemri T, Alnemri E
S. Spodoptera frugiperda caspase-1, a novel insect death protease that cleaves the nuclear immunophilin FKBP46, is the target of the baculovirus antiapoptotic protein p35. J. Biol. Chem. 272, 3:1421-4.

Arrese, EL, Soulages, JL, 2010: Insect fat body: Energy, metabolism, and regulation. Ann. Rev. Entomol.55:207-25.

Bai, C, Degheele, D, 1988: Characterization of the gut juice and heamolymph proteins of $\mathrm{Ma}$ mestra brassicae L., Pieris brassicae L. and Spodoptera littoralis (Boisd.) larvae and susceptibility to Bacillus thuringiensis var. thuringiensis crystal toxins. Mededelingen van de Faculteit landbouwwetenschappen Rijksuniversi teit Gent. 53, 1:255-9.

Bancroft, JD, Cook, HC, 1994: Manual of Histological Techniques and their Diagnostic Application: Churchill Livingstone

Barakat, EM, Meshrif, WS, \& Shehata, MG, 2002: Changes in the haemolymph of the desert locust, Schistocerca gregaria after injection with Bacillus thuringiensis. J. Egypt. Acad. Soc. Environ. Dev. 2:95-115.

Bozzola, JJ, Russell, LD, 1999: Electron microscopy: principles and techniques for biologists. Jones \& Bartlett Learning;.

Brehélin, M, 1982: Comparative study of structure and function of blood cells from two Drosophila species. Cell Tissue Res. 221, 3:607-15.

Chakrabarti, S LP, Buchon, N, Lemaitre, B, 2012: Infection-induced host translational blockage inhibits immune responses and epithelial renewal in the Drosophila gut. Cell Host Microbe 19,1:60-70.

Chen, HM, Wang, W, Smith, D, Chan, SC, 1997: Effects of the anti-bacterial peptide cecropin B and its analogs, cecropins B-1 \& B-2, on liposomes, bacteria, \& cancer cells. BBA. 1336, 2:171-179.

Chowdhury, I, Tharakan, B, Bhat, GK, 2008: Caspases-an update. comparative biochemistry and physiology Part B. J. Biochem. Mol. Biol. 151,1:10-27.

Duan, WR, Garner, DS, Williams, SD, Funckes-Shippy, CL, Spath, IS, et al, 2003: Com-parison of immunohistochemistry for activated caspase- 3 and cleaved cytokeratin 18 with the TUNEL method for quantification of apoptosis in histological sections of PC-3 subcutaneous xenografts. J. Pathol.199,2:221-8.

Eslin, P, Prevost, G, 1996: Variation in Drosophila concentration of haemocytes associated 
with different ability to encapsulate Asobara tabida larval parasitoid. J. Insect Physiol. 42, 6: 549-55.

Feng, G, Yu, Q, Hu, C, Wang, Y, Yuan, G, et $\boldsymbol{a l}$, 2007: Apoptosis is induced in the haemolymph and fat body of Spodoptera exigua larvae upon oral inoculation with Spodoptera litura nucleopolyhedrovirus. J. General Virol. 88, 8: 2185-93.

Gao, D, Qiao, P, Liu, S, Zhang, L, He, P, et al, 2013: Cadmium induces liver cell apoptosis via caspase-3A activation in purse red common carp (Cyprinus carpio). PLoS One. 8, 12:e83423.

Haunerland, N, Shirk, P, 1995: Regional and functional differentiation in the insect fact body. Annu. Rev. Entomol.40,1:121-45.

Hillyer, JF, 2016: Insect immunology and hematopoiesis. Dev. Comp. Immunol.58:102-18.

Jiangfan, X, Tao, W, Yu, W, Jianwei, W, Guo, G, et al, 2016: Histological observation and expression patterns of antimicrobial peptides during fungal infection in Musca domestica (Diptera: Muscidae) Larvae. Braz. Arch. Biol. Technol. 59:56

Keeley, LL, 1985: Physiology and biochemistry of the fat body. Comprehensive insect physiology. Biochemi. Pharmacol.3:211-48.

Khalil, S, Jacobson, E, Chambers, MC, Lazzaro, BP, 2015: Systemic bacterial infection and immune defense phenotypes in Drosophila melanogaster. JOVE 99:e52613.

King, JG HJ, 2013: Spatial and temporal in vivo analysis of circulating and sessile immune cells in mosquitoes: hemocyte mitosis following infection. BMC Biol. 11,1:55.

Klepsatel, P, Gáliková, M, Xu, Y, Kühnlein, RP, 2016: Thermal stress depletes energy reserves in Drosophila. Sci. Repts. 19, 6: 33667.

Kültz, D, 2005: Molecular and evolutionary basis of the cellular stress response. Ann. Rev. Physiol.17, 67: 225-7.

Labbe, K, Saleh, M, 2008: Cell death in the host response to infection. Cell Death Differ. 15, 9:1339-49.

Lemaitre, B, Hoffmann, J, 2007: The host defense of Drosophila melanogaster. Ann. Rev. Immunol. 23,25:697-743.

Li, T, Yan, D, Wang, X, Zhang, L, Chen, P, 2019: Hemocyte changes during immune melanization in Bombyx mori infected with Escher-i chia coli. Insects 10,9:301.

Lipovšek, S, Janžekovič ,F, Novak, T, 2017: Ultrastructure of fat body cells and Malpighian tubule cells in overwintering Scoliopteryx libatrix (Noctuoidea). Protoplasma. 254,6:2189-99.

Masova, A, Sindelka, R, Kubista, M, Kindl, J, Jiracek, J, 2009: Gene expression responses in larvae of fleshfly Sarcophaga bullata after immune stimulation. Folia Biol. (Praha).55, 3:98-106 Matsumoto, Y, Miyazaki, S, Fukunaga, D, Shimizu, K, Kawamoto, S, et al, 2012: Quantitative evaluation of cryptococcal pathogenesis and antifungal drugs using a silkworm infection model with Cryptococcus neoformans. J. Appl. Microbiol.112,1:138-46.

Mishra, S, Kumar, P, Malik, A, 2015: The effect of Beauveria bassiana infection on cell mediated and humoral immune response in house fly, Musca domestica L. Environ. Sci. Pollut. Res. 22,19:15171-8.

Mizerska-Dudka, M, Andrejko, M, 2014: Galleria mellonella hemocytes destruction after infection with Pseudomonas aeruginosa. J. Basic Microbiol. 54, 3:232-46.

Nappi, A, 1981: Cellular immune response of Drosophila melanogaster against Asobara tabida. Parasitol. 83,2:319-24.

Ohta, M, Watanabe, A, Mikami, T, Nakajima, Y, Kitami, M, et al, 2006: Mechanism by which Bombyx mori hemocytes recognize microorganisms: direct and indirect recognition syst ems for PAMPs. Dev. Comp. Immunol. 30, 10: 867-77.

Ratcliffe, N, Azambuja, P, Mello, CB, 2014: Recent advances in developing insect natural products as potential modern day medicines. Evid. Based Complement. Altern. Med. 2014:1-21

Ribeiro, C, Brehélin, M, 2006: Insect hemocytes: what type of cell is that? J. Insect Physiol. 52, 5:417-29.

Rivers, DB, Keefer, DA, Ergin, E, Uçkan, F, 2011: Morphology and ultrastructure of brain tissue and fat body from the flesh fly, Sarcophaga bullata Parker (Diptera: Sarcophagidae), envenomated by the ectoparasitic wasp Nasonia vitrippennis (Walker)(Hymenoptera: Pteromalidae). Psyche: J. Entomol. 2011:1-10

Russo, J, Brehelin, M, Carton, Y, 2001: Haemocyte changes in resistant and susceptible strains of D. melanogaster caused by virulent \& avirulent strains of the parasitic wasp Leptopilina boulardi. J. Insect Physiol.47, 2:167-72.

Scott, JG, Warren, WC, Beukeboom, LW, Bopp, D, Clark, AG, et al, 2014: Genome of the house fly, Musca domestica L., a global vector of diseases with adaptations to a septic envir- 
onment. Genome Biol. 15, 10:466-9.

Shehata, AZ, Mehany, AB, El-Sheikh, TM, 2016: Excretion/secretion of Lucilia sericata and Chrysomya albiceps (Diptera: Calliphoridae) maggots as potential anticancer agent and kinases inhibitor. New York Sci. J. 9, 12:95-101 Singh, S, Reese, JM, Casanova-Torres, ÁM, Goodrich-Blair, H, Forst, S, 2014: Microbial population dynamics in the hemolymph of Manduca sexta infected with Xenorhabdus nemato phila and the entomopathogenic nematode Steinernema carpocapsae. Appl. Environ. Microbiol. 80, 14: 4277-85.

Takahashi, H, Komano, H, Natori, S, 1986: Expression of the lectin gene in Sarcophaga peregrina during normal development and under conditions where the defence mechanism is acti vated. J. Insect Physiol. 32, 9:771-9.

Wu, M, Sugimura, Y, Iwata, K, Takaya, N, Takamatsu, D, et al, 2014: Inhibitory effect of gut bacteria from the Japanese honey bee, Apis cerana japonica, against Melissococcus plutonius, the causal agent of European foulbrood disease. J. Insect Sci.14:1-9.

Xia, Q, Sun, H, Hu, X, Shu, Y, Gu, D, et al, 2005: Apoptosis of Spodoptera litura larval hemocytes induced by heavy metal zinc. CSB. 50, 24:2856-60.

Zakaria, M, 2007: The cellular immunity responses in the haemolymph of honey bee workers infected by american foulbrood disease (AFB). J. Appl. Sci. Res. 3,1:56-63.

\section{Explanation of Figures}

Fig. 1: Light micrographs of S. argyrostoma for hemocytes from control (C) and injected larvae (24, 48 and $72 \mathrm{~h}$ PI.); red arrows indicate nodule formation. Scale bar: $50 \mu \mathrm{m}$.

Fig. 2: TEM micrographs of S. argyrostoma normal larval hemocytes. N - Nucleus; $\mathrm{n}$ - nucleolus; $\mathrm{M}$ - cell membrane. Chr. - Chromatin. Pl- Plasmatocyte, Gr-Granulocytes, SP-Spherulocyte, Oe-Oenocyte..

Fig. 3: TEM micrographs of S.argyrostoma hemocytes from challenged larvae at 24, $48 \& 72 \mathrm{hr}$; N - Nucleus; V - Vacuole with heterogeneous material; Chr-Chromatin; $\mathrm{M}$ - cell membrane. $\mathrm{P}$ - pinocytic vesicles; red arrow indicate blebbing membrane.

Fig. 4: Light micrographs of $S$. argyrostoma normal larval fat body cells (C) and challenged larvae at 24,48 and $72 \mathrm{~h}$ post injection. NNucleus; LD- Lipid droplets; V - Vacuole; M - Cell membrane; P - Protein granules; red arrows totally disintegrated cells. Scale bar: $50 \mu \mathrm{m}$

Fig. 5: TEM micrographs of $S$. argyrostoma normal larval fat body cells of control(C) and injected larvae at 24,48 and $72 \mathrm{~h}$ post injection. N- Nucleus; LD- Lipid droplets; V - Vacuole; M - Cell membrane; P - Protein granules.

Fig. 6: Caspase-3 immunohistochemical detection of cell death in larval fat body tissues of S. argyrostoma from control (C) and challenged larvae at 24, $48 \& 72 \mathrm{hr}$. Positive reactions brown color. N- Nucleus; V - Vacuole; M - Cell membrane; Fb - Fat body; Scale bar: $50 \mu \mathrm{m}$
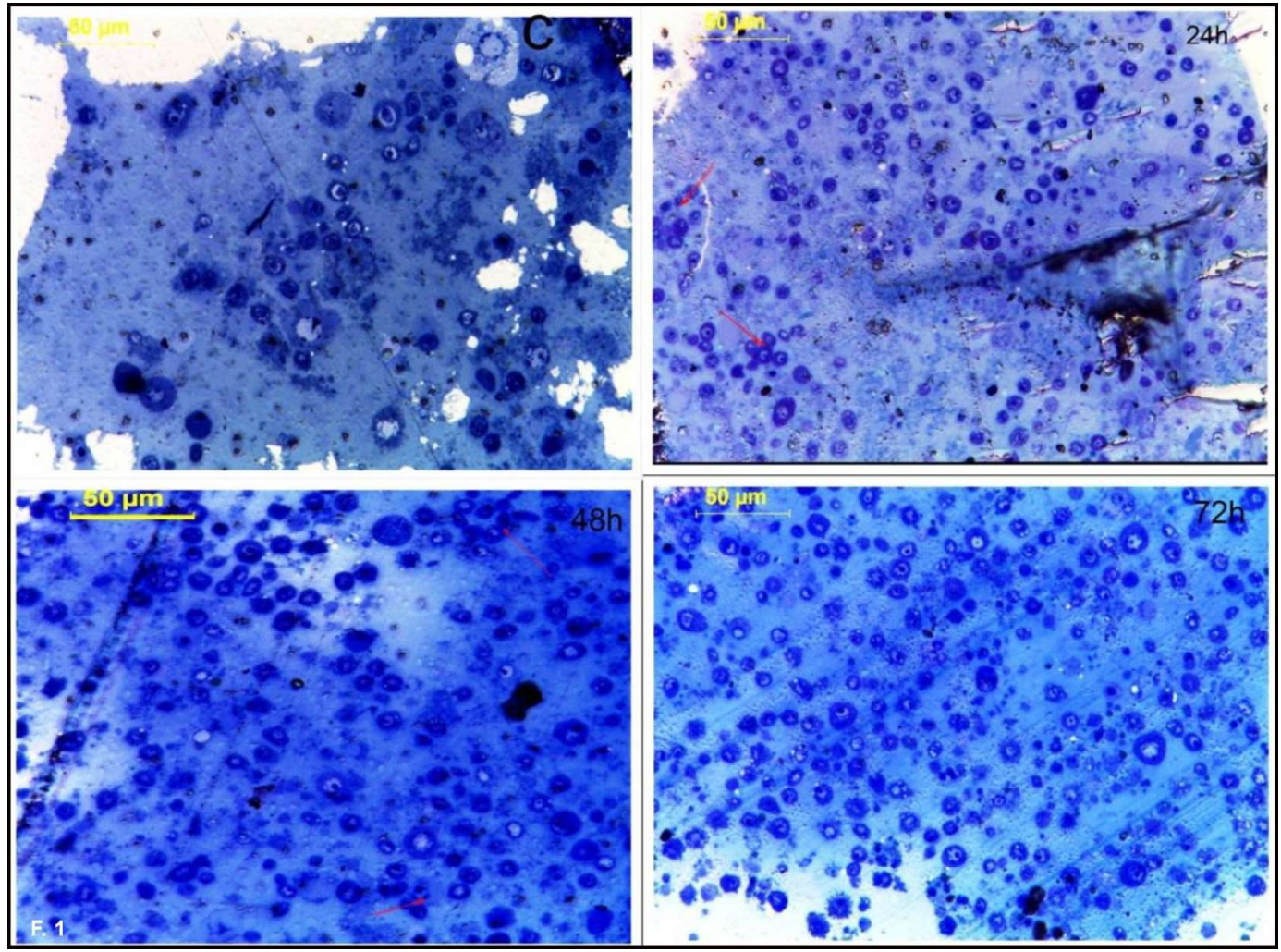


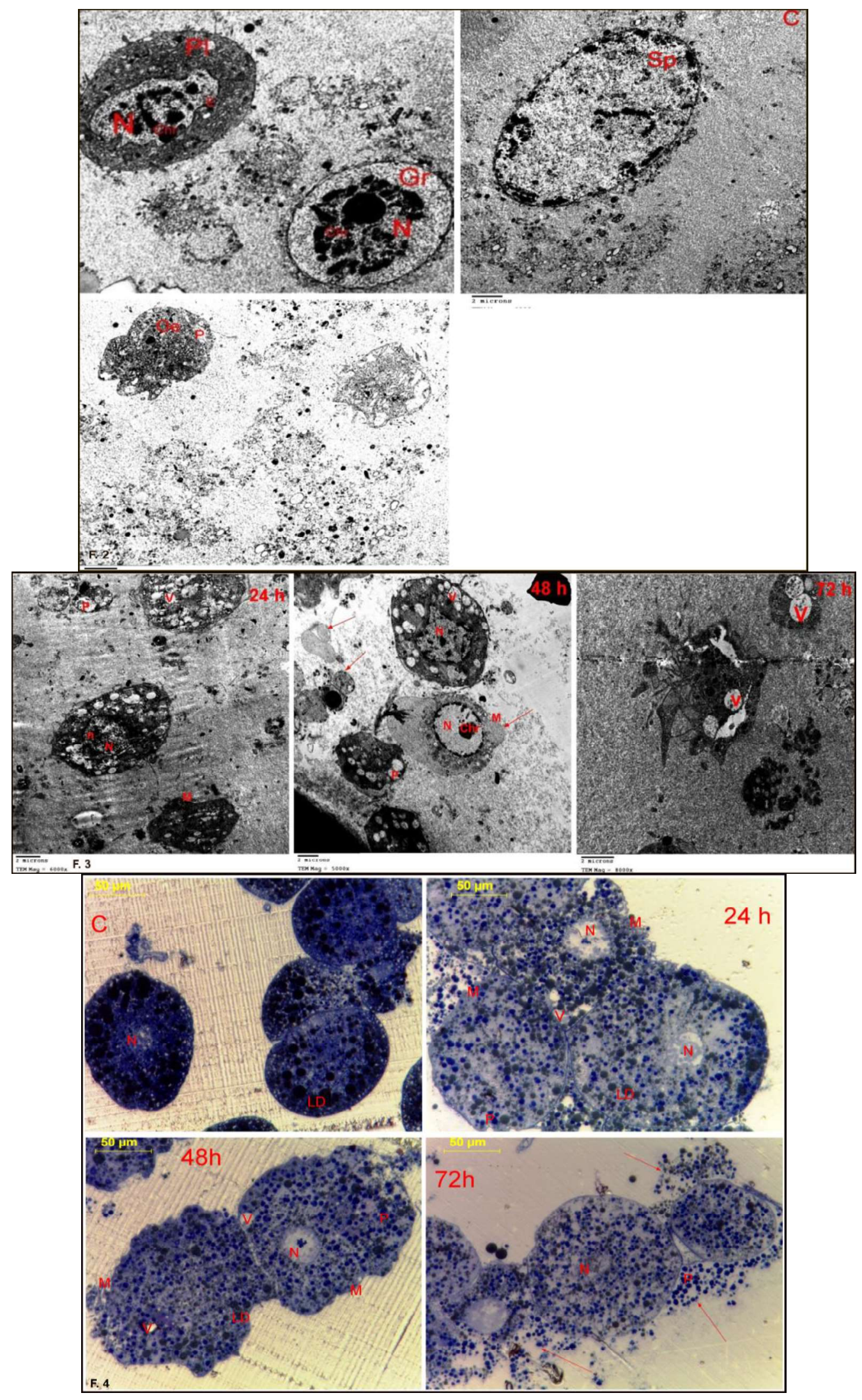




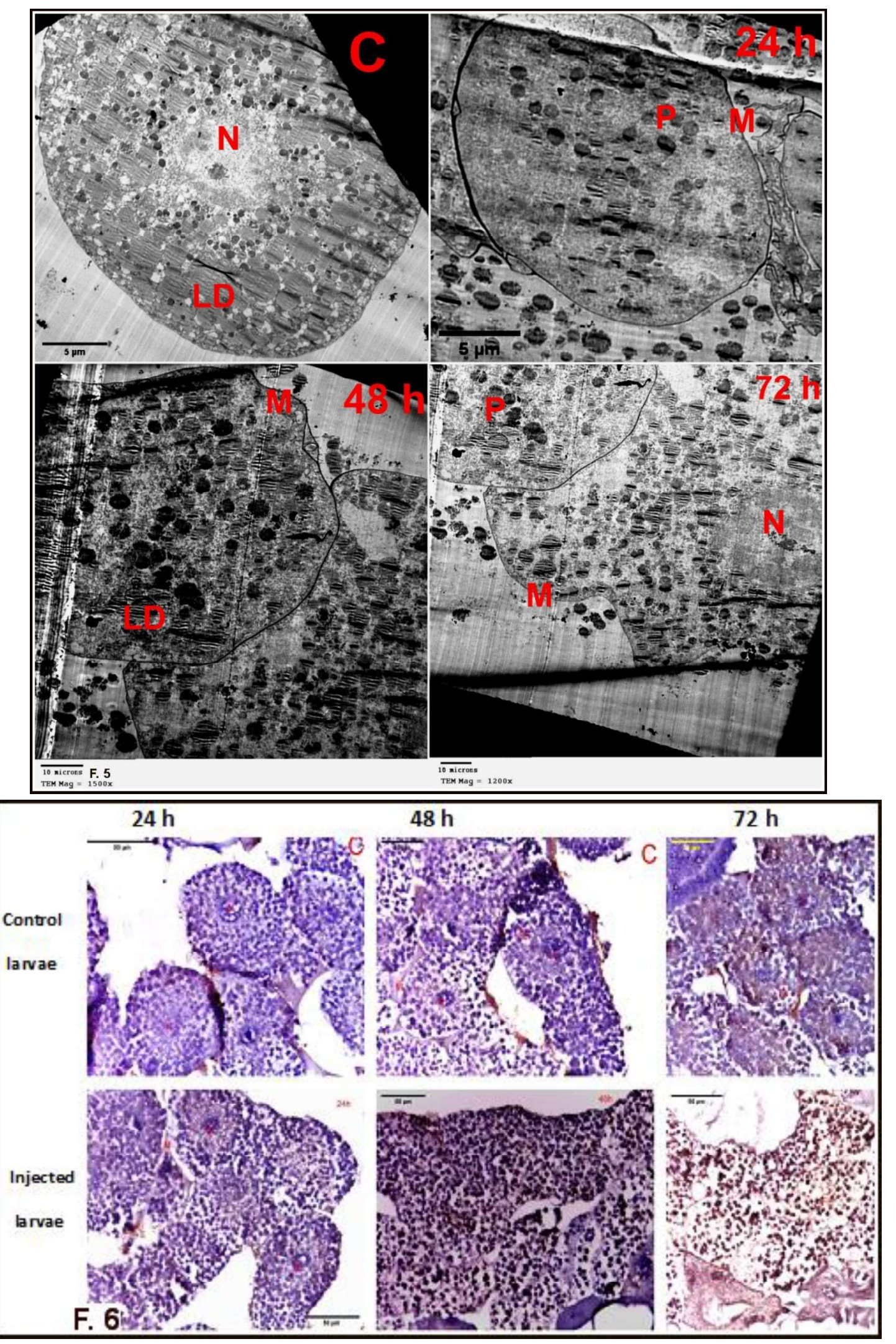

